\title{
Model Pemberdayaan Ibu dalam Mencegah Stunting di Wilayah Pedesaan
}

\author{
Resti Utami, Siti Kholifah
}

Universitas Muhammadiyah Jember, Fakultas Ilmu Kesehatan, Program Studi D3

Keperawatan, Jl. Karimata No. 49 Sumbersari, Jember, Jawa Timur

Email: resti.utami@unmuhjember.ac.id

\author{
Diterima tanggal : 16 Juni 2020 \\ Direvisi tanggal : 12 Agustus 2020 \\ Dipublikasikan tanggal : 10 Desember 2020
}

\begin{abstract}
Abstrak
Latar Belakang dan Tujuan: Pemberdayaan ibu dikaitkan dengan peningkatan gizi anak, dan keduanya mendukung pencapaian beberapa tujuan Pembangunan Berkelanjutan (SDGs). Tujuan penelitian ini adalah untuk menemukan suatu model pemberdayaan ibu dalam mencegah stunting di wilayah pedesaan. Penelitian menggunakan metode analitik deskriptif pendekatan cross sectional.

Metode: Desain penelitian menggunakan analitik deskriptif dengan pendekatan cross sectional. Pengumpulan data menggunakan data sekunder dan buku KIA. Penelitian dilakukan di Desa Biting, wilayah kerja Puskesmas Arjasa. Sampel dalam penelitian sebesar 100 responden. Penelitian mengoperasionalkan pemberdayaan ibu dengan menggunakan tiga domain resources (lingkar lengan atas/LILA, usia ibu, pendidikan ibu), agency (keputusan pemberian asi eksklusif), dan achievements (status gizi balita). Analisis statistik dalam penelitian ini menggunakan Partial Least Squares.

Hasil: Model pemberdayaan ibu yang didasarkan pada kerangka kerja Kabeer (1999) yang terdiri dari resources, agency, dan achievements telah fit berpengaruh dalam mencegah stunting di wilayah pedesaan yang ditunjukan dengan nilai GoF 0,773 dan predictive relevance 0,643 mendekati nilai 1 .

Simpulan dan Implikasi: Temuan ini memberikan beberapa penjelasan dan implikasi potensial bahwa: 1) pemberdayaan ibu berfungsi sebagai jalur dasar untuk mencegah stunting terutama meningkatkan gizi balita, 2) peningkatan ini dapat berasal dari peningkatan agency ibu yang berkaitan dengan keputusan untuk memberikan ASI eksklusif, 3) mekanisme biologis dan sosial dimana usia, nutrisi yang memadai dari wanita sebelum dan selama kehamilan (ditunjukan dengan indikator kecukupan energi lingkar lengan atas/LILA), dan pendidikan ibu mengoptimalkan transfer informasi ibu dalam mendukung keputusan pemberian asi eksklusif yang pada akhirnya dapat berkontribusi dalam mencegah stunting dengan meningkatkan gizi balita.
\end{abstract}

Kata Kunci : Balita; Pencegahan stunting; Pemberdayaan ibu; Stunting

Sitasi: Utami R \& Kholifah S. (2020). Model pemberdayaan ibu dalam mencegah stunting di wilayah pedesaan. The Indonesian Journal of Health Science. 12(2), 110-120

Copyright: () 2020 Utami et al. This is an open-access article distributed under the terms of the Creative Commons Attribution-NonCommercial 4.0 International License, which permits unrestricted use, distribution, and reproduction in any medium, provided the original author and source are credited.

Diterbitkan Oleh: Universitas Muhammadiyah Jember

ISSN (Print): 2087-5053

ISSN (Online): 2476-9614 


\begin{abstract}
Introduction and Aim: Mother empowerment is associated with improving children's nutrition, and both support the achievement of several Sustainable Development goals (SDGs). The purpose of this study was to find a model of mother empowerment to prevent stunting in rural areas.

Methods: The study used a descriptive-analytic method with a cross-sectional approach. Data collection uses secondary data and KIA books. The study was conducted in Biting Village, the working area of the Arjasa Health Center. Sample in the study was 100 respondents. The study operationalized maternal empowerment by using three resource domains (upper arm circumference, maternal age, maternal education), agency (decisions on exclusive breastfeeding), and achievements (nutritional status of children under five). The statistical analysis in this study used Partial Least Squares.

Results: Mother empowerment model based on the Kabeer framework (1999) consisting of resources, agency, and achievements had a fit effect in preventing stunting in rural areas as indicated by a GoF value of 0.773 and predictive relevance of 0.643 approaching a value of 1 .

Conclusion: This finding provides several explanations and potential implications that 1) Mother empowerment serves as a basic pathway to prevent stunting, especially improving under-fives nutrition; 2) this increase can originate from an increase in a maternal agency related to the decision to provide exclusive breastfeeding; 3) biological mechanisms and social conditions where age, adequate nutrition of women before and during pregnancy (indicated by indicators of energy sufficiency of the upper arm circumference/MUAC), and mother education optimize the transfer of maternal information to support of exclusive breastfeeding decisions which can ultimately contribute to preventing stunting by increasing toddler nutrition.
\end{abstract}

Keywords: Empowering mothers; Preventing stunting; Stunting, Toddlers

\section{PENDAHULUAN}

Stunting masih menjadi salah satu gangguan pertumbuhan dan perkembangan anak-anak di bawah usia lima tahun (Sjarif, Yuliarti, \& Iskandar, 2019; Tanaka, Yoshizawa, Hirayama, Karama, \& Wanjihia, 2019). Stunting dapat menyebabkan peningkatan morbiditas dan mortalitas penyakit menular, gangguan perkembangan kognitif dan mental pada anak, hingga produktivitas yang rendah saat dewasa (Yang et al., 2018). Secara khusus, stunting merujuk kepada anak usia 0 hingga 59 bulan yang berada $<-2$ SD dari tinggi rata-rata untuk usia yang ditentukan oleh standar dari World Health Organization (WHO) (Fenta, Workie, Zike, Taye, \& Swain, 2019)
Indonesia

menduduki peringkat kelima kejadian stunting pada balita di dunia (Sjarif et al., 2019). Prevalensi balita stunting mengalami penurunan dari $37,2 \%$ menjadi $30.8 \%$ (Riskesdas, 2018). Namun demikian, tantangan percepatan penurunan stunting masih cukup besar karena berada diatas standar yang ditetapkan World Health Organization (WHO) yaitu dibawah 20 persen, sehingga Indonesia termasuk wilayah yang mengalami permasalahan gizi akut.

Banyak faktor yang mempengaruhi terjadinya stunting pada balita seperti faktor ibu, faktor balita, dan lingkungan (Fenta et al., 2019). Ibu mempengaruhi status kesehatan balita (Utami, Setiawan, \& Fitriyani, 2019). Ibu adalah pemberi asuhan primer bagi balita (Heckert, 
Olney, \& Ruel, 2019). Balita memerlukan ibu dalam memenuhi kebutuhan gizinya. Dengan demikian, ibu memiliki peranan penting dalam melakukan upaya pencegahan stunting pada balita.

Salah satu hal yang dapat dilakukan dalam mencegah stunting adalah dengan memberdayakan ibu. Para ahli mendefinisikan pemberdayaan ibu sebagai kemampuan seorang ibu untuk menggunakan sumber daya yang memungkinkan, dan bertindak berdasarkan keinginan untuk mengubah hidup (Jones et al., 2019). Pemberdayaan ibu menjadi salah satu penentu yang mendasari gizi balita dengan bukti substansial secara positif mempengaruhi pertumbuhan dan perkembngan balita (Heckert et al., 2019; Jones et al., 2019). Pemberdayaan ibu telah dikaitkan dengan praktik-praktik yang secara tidak langsung mempengaruhi gizi balita seperti usia ibu saat hamil, riwayat pemberian asi eksklusif, kesehatan ibu selama hamil (lingkar lengan atas), jarak kelahiran, kesehatan mental, dan akses pelayanan kesehatan (Holland \& Rammohan, 2019; Jones et al., 2019). Memberdayakan ibu sebagai bagian dari program dalam mencegah stunting didukung oleh semakin banyak bukti empiris yang menyimpulkan bahwa ibu yang diberdayakan memiliki anak dengan hasil gizi yang lebih baik. Namun studi tersebut terutama menarik kesimpulan dari studi asosiasi menggunakan data cross-sectional, gagal memberikan bukti tentang apakah memberdayakan ibu dalam mencegah stunting mengarah pada peningkatan status gizi balita (Heckert et al., 2019). penting dalam upaya dalam mencegah stunting pada balita. Sejalan dengan Strategi Nasional Percepatan Pencegahan Stunting 2018-2024 maka perawat perlu mengidentifikasi faktor yang mempengaruhi pemberdayaan ibu dalam mencegah stunting pada balita untuk menentukan strategi yang tepat dalam mencegah stunting dengan melakukan penelitian eksplorasi.

Puskesmas

Arjasa merupakan puskesmas dengan jumlah balita stunting tertinggi daerah pedesan di Kabupaten Jember yaitu sebesar $67 \%$ sedangkan, untuk daerah perkotaan jumlah balita stunting tertinggi ada di wilayah kerja Puskesmas Patrang (27,27\%) dan Puskesmas Mangli (14\%). Data karakteristik wilayah tempat tinggal menunjukkan bahwa prevalensi stunting tahun 2013 sebagian besar terjadi di pedesaan. Prevalensi stunting tahun 2013 di wilayah pedesaan adalah $42,1 \%$, dan wilayah perkotaan sebesar 32,5\% (Aridiyah, Rohmawati, \& Ririanty, 2015). Hasil wawancara yang dilakukan kepada petugas kesehatan di Puskesmas Arjasa mengatakan program pencegahan stunting yang ada masih sebatas pada pemberian program imunisasi, pemberian makanan sehat pada balita dan ibu hamil di posyandu, dan belum ada suatu model pemberdayaan ibu dalam mencegah stunting di wilayah Puskesmas Arjasa. Dengan demikian, maka perlu dilakukan penelitian untuk mendapatkan suatu model pemberdayaan ibu dalam mencegah stunting dengan menggunakan kerangka kerja Kabeer (1999) yang terdiri dari tiga domain yaitu resources, agency, dan achievements (Jones et al., 2019). 


\section{METODE PENELITIAN}

Penelitian ini menggunakan metode analitik deskriptif dengan pendekatan cross sectional. Pengumpulan data mennggunakan data sekunder dan buku KIA. Penelitian dilakukan di Desa Biting, wilayah kerja Puskesmas Arjasa. Penelitian mengadaptasi kerangka yang diusulkan oleh Kabeer (1999) untuk menggambarkan kemungkinan aset manusia dan sosial serta dimensi terpilih dari agensi perempuan dalam mencegah stunting. Penggunaan kerangka kerja ini bertujuan untuk menemukan suatu model pemberdayaan ibu dalam mencegah stunting di wilayah pedesaan.

$$
\text { Penelitian menggunakan }
$$

analisis data sekunder dan buku KIA dari Puskesmas Arjasa. Sampel dalam penelitian sebesar 100 responden. Penelitian mengoperasionalkan pemberdayaan ibu dengan menggunakan tiga domain resources (lingkar lengan atas/LILA, usia ibu, pendidikan ibu), agency (keputusan pemberian asi eksklusif), dan achievements (status gizi balita). Analisis statistik dalam penelitian ini menggunakan Partial Least Squares (Rasoolimanesh \& Ali, 2018; Sarstedt, Ringle, \& Hair, 2020). Penelitian ini diawali dengan mengajukan ethical clearance terlebih dahulu yang dilakukan oleh tim etik Fakultas Ilmu Kesehatan Universitas Muhammadiyah Jember yang mengacu pada Komisi Etik Penelitian dan Pengembangan Kesehatan Nasional (KEPPN, 2017).

\section{HASIL}

\section{Pengujian measurement (outer) model}

Validitas

(convergent

validity) tampak pada gambar 1. Dari nilai outer loading untuk semua indikator baik dari indikator untuk variabel laten seperti resources, agency, dan achievements diketahui bahwa semua indikator valid. dengan nilai outer loading $>0,5$. Hal tersebut menunjukkan bahwa indikator tersebut di dalam struktural telah memenuhi uji validitas (Tabel 1).

Sedangkan untuk nilai reliabilitas diketahui dari nilai composite reliability dan cronbachs alpha memiliki nilai >0,7 sehingga dapat disimpulkan bahwa semua variabel laten (resources, agency, achievements) telah memenuhi uji reliabilitas. Untuk menunjukkan convergent validity menggunakan nilai average variance extacted (AVE). Berdasarkan nilai AVE untuk semua variabel laten adalah diatas 0,5 (sangat direkomendasikan) (Tabel 2).

\section{Pengujian model struktural (inner) model}

Penelitian ini menghasilkan evaluasi inner model (hipotesis diterima jika nilai $\mathrm{t}$ hitung $>\mathrm{t}$ tabel dengan $\alpha 5 \%$ yang ditunjukkan oleh nilai t statistik $>2,0$ ). Nilai koefisien jalur dan nilai $t$ hitung pada inner model. Berdasarkan tabel 3 menunjukkan bahwa agency terhadap achievements ( $\mathrm{t}$ statistik $4,169<2,0)$, resources terhadap achievements ( $\mathrm{t}$ statistik $1,046<2,0$ ), dan resources terhadap agency $(\mathrm{t}$ statistik $9,169>2,0)$ dengan demikian, resources berpengaruh langsung terhadap agency dan berpengaruh secara tidak langsung terhadap achievements. Resources memiliki pengaruh positif yang signifikan dalam mencegah stunting dengan koefisien jalur $(0,713)$ sehingga resources merupakan faktor yang paling berpengaruh kuat dalam 
mencegah stunting pada balita. Nilai $\mathrm{R}$ square $\left(\mathrm{R}^{2}\right)$ untuk kontrak atau variabel laten model pemberdayaan ibu dalam mencegah stunting.

Berdasarkan tabel 4 menunjukkan bahwa resources mampu menjelaskan secara langsung variability konstrak atau variabel laten agency sebesar 50,8\% (nilai $\mathrm{R}^{2}$ ), dan secara tidak langsung mampu menjelaskan variability konstrak atau variabel laten achievements sebesar $64,3 \%$ dan sisanya $35,7 \%$ diterangkan oleh konstrak lainnya yang tidak dihipotesiskan dalam model. Untuk memvalidasi model secara keseluruhan, dapat dilihat dari Goodness of Fit (GoF) absolute (Persamaan 1). Nilai GoF untuk model pemberdayaan ibu dalam mencegah stunting diatas adalah 0,773 yang berarti bahwa model yang ditemukan adalah model yang baik karena mendekati nilai 1 .

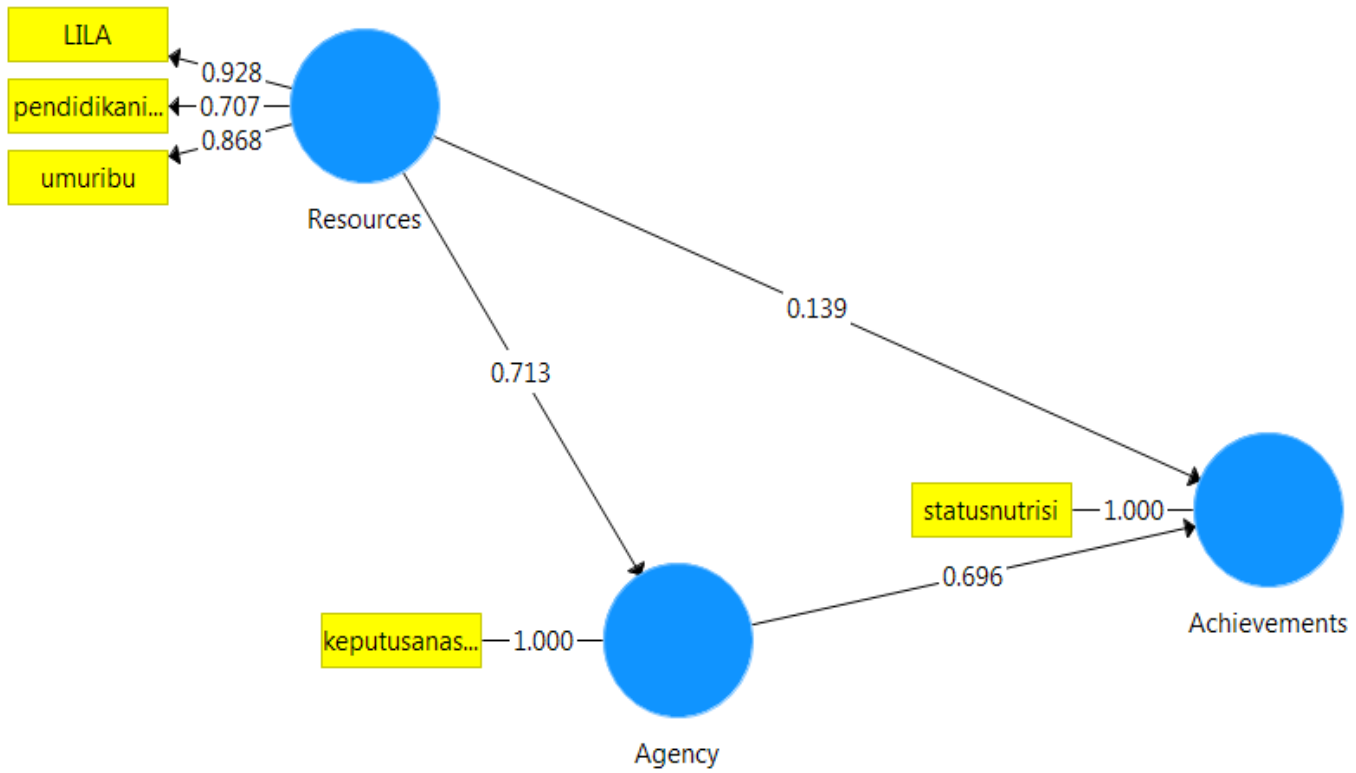

Gambar 1. Hasil Uji Validitas (Convergen Validity)

Tabel 1. Hasil Convergent Validity Model Pemberdayaan Ibu dalam Mencegah Stunting

\begin{tabular}{|c|c|c|c|c|}
\hline Variabel & Indikator & & Outer Loading & Keterangan \\
\hline $\begin{array}{l}\text { Resources } \\
\text { (X1) }\end{array}$ & $\begin{array}{l}\text { X1.1 LILA } \\
\text { X1.2 Pendidikan ibu } \\
\text { X1.3 Umur ibu }\end{array}$ & & $\begin{array}{l}0.928 \\
0,707 \\
0,868\end{array}$ & $\begin{array}{l}\text { Valid } \\
\text { Valid } \\
\text { Valid }\end{array}$ \\
\hline $\begin{array}{l}\text { Agency } \\
\text { (X2) }\end{array}$ & $\begin{array}{l}\text { X2.1 Keputusan } \\
\text { Eksklusif }\end{array}$ & ASI & 1,000 & Valid \\
\hline $\begin{array}{l}\text { Achievements } \\
\text { (X3) }\end{array}$ & X3.1 Status nutrisi & & 1,000 & Valid \\
\hline
\end{tabular}

$$
\begin{aligned}
\text { GoF } & =\sqrt{ } \operatorname{Com} \times \sqrt{ } R^{2} \\
& =0,773
\end{aligned}
$$

Persamaan 1. Goodness of Fit (GoF) absolute 
Tabel 2. Hasil Average Variance Extracted (AVE), Composite reliability, dan Cronbachs alpha Model Pemberdayaan Ibu dalam Mencegah Stunting

\begin{tabular}{lcccc}
\hline \multicolumn{1}{c}{ Variabel } & $\boldsymbol{A} \boldsymbol{V E}$ & $\begin{array}{c}\text { Composite } \\
\text { reliability }\end{array}$ & $\begin{array}{c}\text { Cronbachs } \\
\text { alpha }\end{array}$ & Keterangan \\
\hline Resources (X1) & 0,705 & 0,876 & 0,782 & Reliabel \\
Agency (X2) & 1,000 & 1,000 & 1,000 & Reliabel \\
Achievements (X3) & 1,000 & 1,000 & 1,000 & Reliabel \\
\hline
\end{tabular}

Tabel 3. Hasil Uji Hipotesis Model Pemberdayaan Ibu dalam Mencegah Stunting

\begin{tabular}{l|c|c|c}
\hline \multicolumn{1}{c|}{ Variabel } & $\begin{array}{c}\text { Original } \\
\text { sampel (0) }\end{array}$ & T statistic & Keterangan \\
\hline $\begin{array}{l}\text { Pengaruh agency (Y1) terhadap } \\
\text { achievements }(\mathrm{Y} 2)\end{array}$ & 0,696 & 4,169 & Ada pengaruh \\
\hline $\begin{array}{l}\text { Pengaruh resources (X1) } \\
\text { terhadap achievements (Y2) }\end{array}$ & 0,139 & 1,046 & Tidak ada pengaruh \\
\hline $\begin{array}{l}\text { Pengaruh resources (X1) } \\
\text { terhadap agency (Y1) }\end{array}$ & 0,713 & 9,169 & Ada pengaruh \\
\hline
\end{tabular}

Tabel 4. Hasil R2 Model Pemberdayaan Ibu dalam Mencegah Stunting

\begin{tabular}{lcccc}
\hline \multicolumn{1}{c}{ Variabel } & $\boldsymbol{A V E}$ & $\begin{array}{c}\text { Composite } \\
\text { reliability }\end{array}$ & $\begin{array}{c}\text { Cronbachs } \\
\text { alpha }\end{array}$ & $\mathbf{R}^{\mathbf{2}}$ \\
\hline Agency (Y1) & 1,000 & 1,000 & 1,000 & 0.508 \\
\hline Achievements (Y2) & 1,000 & 1,000 & 1,000 & 0,643 \\
\hline
\end{tabular}

\section{PEMBAHASAN}

Hasil penelitian menunjukkan bahwa resources tidak berpengaruh signifikan terhadap achievements dalam mencegah stunting. Faktor resouces yang terdiri dari umur ibu saat hamil, lingkar lengan atas ibu saat hamil (LILA), dan pendidikan ibu tidak mempengaruhi secara langsung achievements (pencapaian) dalam hal status gizi balita yang diukur dengan indikator TB/U. Usia ibu saat hamil dan lingkar lengan atas ibu saat hamil (LILA) bukanlah prediktor utama secara langsung dalam pencapaian status gizi balita (Mohidul Islam, Shahinur Rahman, Kamruzzaman, Mominul Islam, 2013). Hal ini sejalan dengan penelitian Liswati (2016) mengatakan bahwa tidak ada hubungan signifikan antara umur ibu dengan status gizi balita. Faktor umur ibu merupakan faktor secara tidak langsung mempengaruhi status gizi pada balita.
Demikian halnya pendidikan ibu tidak berpengaruh secara langsung terhadap pencapaian (achievements) status gizi balita. Hal ini didukung oleh penelitian Sukmawati, Hendrayati, Chaerunnimah, \& Nurhumaira (2018) mengatakan bahwa tidak ada hubungan antara pendidikan ibu dengan status gizi pada balita. Hal ini dapat terjadi karena secara tidak langsung terdapat faktor lainnya seperti sikap ibu dalam memberikan asi eksklusif dimana penelitian yang dilakukan oleh Nadkarni (2015) mengatakan bahwa ibu dengan pendidikan kurang dari sekolah menengah secara signifikan lebih cenderung menyusui secara eksklusif untuk waktu yang lebih singkat dan memulai pemberian susu formula sejak dini sehingga hal ini dapat berpengaruh terhadap capaian status nutrisi balita.

Lingkar lengan atas ibu saat hamil (LILA) tidak berpengaruh 
secara langsung terhadap pencapaian (achievements) status gizi balita. Hasil ini tidak sejalan dengan beberapa penelitian yang menyatakan bahwa ada hubungan yang signifikan antara lingkar lengan atas ibu saat hamil (LILA) dengan kejadian stunting pada balita. Hal ini dapat terjadi karena secara tidak langsung terdapat faktor lainnya seperti sikap ibu yang dapat mempengaruhi keyakinan ibu dalam pengambilan keputusan untuk memberikan perawatan terbaik bagi anaknya (asi eksklusif) yang pada akhirnya dapat berdampak terhadap status gizi balita. Dengan demikian, usia ibu saat hamil, lingkar lengan atas ibu saat hamil (LILA), dan pendidikan ibu tidak mempengaruhi secara langsung status nutrisi balita.

Resources berpengaruh signifikan terhadap agency dalam mencegah stunting. Faktor resouces yang terdiri dari umur ibu saat hamil, lingkar lengan atas ibu saat hamil (LILA), dan pendidikan ibu mempengaruhi agency yang diukur dengan indikator keputusan untuk memberikan asi eksklusif. Hal ini didukung oleh penelitian Dennis, Gagnon, Van Hulst, Dougherty, \& Wahoush (2013) dan Kitano et al. (2016) yang mengatakan bahwa usia ibu yang lebih tua ( $>20$ tahun) terkait secara independen dalam keputusan untuk memberikan asi eksklusif. Beberapa penelitian menunjukkan bahwa ibu yang lebih muda, jika dibandingkan dengan ibu yang lebih tua, beresiko menghentikan secara dini praktik pemberian asi eksklusif (Dennis et al., 2013). Dengan demikian, ibu di dalam rentang usia yang lebih tua (21-35 tahun) secara signifikan berhasil dalam praktik pemberian asi eksklusif.
Penelitian yang dilakukan oleh Huynh, Tran, Nguyen, Berde, \& Low (2018) mengatakan bahwa lingkar lengan atas ibu saat hamil (LILA) $(>23 \mathrm{~cm})$ dapat meningkatkan produksi asi. Hal ini berkaitan dengan kondisi kecukupan energi ibu yang baik dimana ditunjukkan dengan indikator lingkar lengan atas (LILA) ( > $23 \mathrm{~cm}$ ) dapat meningkatkan produksi asi yang pada akhirnya hal ini dapat mendukung keputusan ibu untuk memberikan asi eksklusif.

Tingkat pendidikan turut pula menentukan mudah tidaknya seseorang menyerap dan memahami pengetahuan gizi yang diperoleh dimana semakin tinggi pendidikan ibu semakin meningkatkan kemampuan ibu menyerap ilmu pengetahuan praktis dan pendidikan non formal terutama melalui televisi, surat kabar, radio, dan lain-lain sehingga hal ini dapat meningkatkan keputusan ibu untuk memberikan asi esklusif. Studi ini menegaskan peran positif pendidikan ibu terhadap inisiasi menyusui dini. Hubungan antara pendidikan ibu dan inisiasi menyusui dini berada pada tingkat signifikansi marginal untuk ibu dengan pendidikan menengah atau lebih tinggi (Acharya \& Khanal, 2015). Ini menunjukkan semakin pentingnya pendidikan untuk mendukung kebijakan tentang pemberian asi eksklusif. Dengan demikian, faktor resouces yang terdiri dari umur ibu saat hamil, lingkar lengan atas ibu saat hamil (LILA), dan pendidikan ibu berpengaruh secara langsung terhadap agency yang diukur dengan indikator keputusan untuk memberikan asi eksklusif.

$$
\text { Agency berpengaruh }
$$

signifikan terhadap achievements 
dalam mencegah stunting. Faktor agency diukur dengan indikator keputusan untuk memberikan asi eksklusif. Hal ini didukung oleh penelitian Katepa-Bwalya et al. (2015) mengatakan bahwa ada proporsi yang secara signifikan lebih tinggi ( $\mathrm{p}<0,001)$ anak-anak yang diberi ASI eksklusif hingga empat bulan. Analisis hubungan praktik pemberian ASI eksklusif dengan status gizi bayi menunjukkan bahwa di antara 25 bayi yang disusui eksklusif hanya 2 yang ditemukan dengan wasting (Mohidul Islam, Shahinur Rahman, Kamruzzaman, Mominul Islam, 2013). Hal ini menunjukkan bahwa ibu bayi yang memutuskan untuk memberikan asi eksklusif akan berdampak terhadap peningkatan status gizi balita dimana hal ini dapat mencegah terjadinya stunting.

Hasil penelitian menunjukkan bahwa model pemberdayaan ibu menggunakan konstruksi tiga domain yang didasarkan pada kerangka kerja Kabeer (1999) dimana terdiri dari resources, agency, dan achievements telah fit berpengaruh dalam mencegah stunting di wilayah pedesaan yang ditunjukan dengan nilai GoF 0,773 dan predictive relevance 0,643 mendekati nilai 1 . Penggunaan analisis jalur ini memungkinkan pemahaman yang lebih dalam tentang bagaimana domain resources, agency, dan achievements ini berfungsi. Temuan ini memberikan beberapa penjelasan dan implikasi potensial bahwa (1) Pemberdayaan ibu berfungsi sebagai jalur dasar untuk mencegah stunting terutama meningkatkan gizi balita, (2) Peningkatan ini dapat berasal dari peningkatan agency ibu yang berkaitan dengan keputusan untuk memberikan asi eksklusif,
Mekanisme biologis dan sosial di mana usia, nutrisi yang memadai dari wanita sebelum dan selama kehamilan (ditunjukan dengan indikator kecukupan energi lingkar lengan atas/LILA), dan pendidikan ibu mengoptimalkan transfer informasi ibu dalam mendukung keputusan pemberian asi eksklusif yang pada akhirnya dapat berkontribusi dalam mencegah stunting dengan meningkatkan status gizi balita.

\section{SIMPULAN}

Usia ibu saat hamil, lingkar lengan atas ibu saat hamil (LILA), dan pendidikan ibu tidak mempengaruhi secara langsung status nutrisi balita. Faktor resouces yang terdiri dari umur ibu saat hamil, lingkar lengan atas ibu saat hamil (LILA), dan pendidikan ibu berpengaruh secara langsung terhadap agency yang diukur dengan indikator keputusan untuk memberikan asi eksklusif. Ibu bayi yang memutuskan untuk memberikan asi eksklusif akan berdampak terhadap peningkatan status gizi balita dimana hal ini dapat mencegah terjadinya stunting.

Model pemberdayaan ibu yang didasarkan pada kerangka kerja Kabeer (1999) yang terdiri dari resources, agency, dan achievements telah fit berpengaruh dalam mencegah stunting di wilayah pedesaan yang ditunjukan dengan nilai $\mathrm{GoF} 0,773$ dan predictive relevance 0,643 mendekati nilai 1 . Temuan ini memberikan beberapa penjelasan dan implikasi potensial bahwa (1) Pemberdayaan ibu berfungsi sebagai jalur dasar untuk mencegah stunting terutama meningkatkan gizi balita, (2) Peningkatan ini dapat berasal dari 
peningkatan agency ibu yang berkaitan dengan keputusan untuk memberikan asi eksklusif, (3) Mekanisme biologis dan sosial di mana usia, nutrisi yang memadai dari wanita sebelum dan selama kehamilan (ditunjukan dengan indikator kecukupan energi lingkar lengan atas/LILA), dan pendidikan ibu mengoptimalkan transfer informasi ibu dalam mendukung keputusan pemberian asi eksklusif yang pada akhirnya dapat berkontribusi dalam mencegah stunting dengan meningkatkan status gizi balita.

\section{SARAN}

Keluarga perlu diberikan pendidikan kesehatan tentang gizi pada balita dalam mencegah stunting sebagai dasar pengetahuan untuk mendukung dalam pemberian asi eksklusif. Bagi peneliti selanjutnya diharapkan meneliti hubungan variabel lain model pemberdayaan ibu dalam mencegah stunting yang didasarkan pada kerangka kerja Kabeer (1999).

\section{DAFTAR PUSTAKA}

Acharya, P., \& Khanal, V. (2015). The effect of mother's educational status on early initiation of breastfeeding: Further analysis of three consecutive Nepal Demographic and Health Surveys Global health. BMC Public Health, 15(1).

https://doi.org/10.1186/s12889015-2405-y

Aridiyah, F. O., Rohmawati, N., \& Ririanty, M. (2015). Faktorfaktor yang Mempengaruhi Kejadian Stunting pada Anak
Balita di Wilayah Pedesaan dan Perkotaan. Pustaka Kesehatan, 3(1).

Dennis, C. L., Gagnon, A., Van Hulst, A., Dougherty, G., \& Wahoush, O. (2013). Prediction of duration of breastfeeding among migrant and canadianborn women: Results from a multi-center study. Journal of Pediatrics, 162(1), 72-79. https://doi.org/10.1016/j.jpeds.2 012.06.041

Fenta, H. M., Workie, D. L., Zike, D. T., Taye, B. W., \& Swain, P. K. (2019). Determinants of Stunting among under-five Years Children in Ethiopia from the 2016 Ethiopia Demographic and Health Survey: Application of Ordinal Logistic Regression Model using Complex Sampling Designs. Clinical Epidemiology and Global Health. https://doi.org/10.1016/j.cegh.2 019.09.011

Heckert, J., Olney, D. K., \& Ruel, M. T. (2019). Is women's empowerment a pathway to improving child nutrition outcomes in a nutritionsensitive agriculture program?: Evidence from a randomized controlled trial in Burkina Faso. Social Science and Medicine, 233(April), 93-102. https://doi.org/10.1016/j.socsci med.2019.05.016

Holland, C., \& Rammohan, A. (2019). Rural women's empowerment and children's food and nutrition security in Bangladesh. World Development, $\quad 124$. https://doi.org/10.1016/j.worldd ev.2019.104648

Huynh, D. T. T., Tran, N. T., Nguyen, L. T., Berde, Y., \& 
Low, Y. L. (2018). Impact of maternal nutritional supplementation in conjunction with a breastfeeding support program on breastfeeding performance, birth, and growth outcomes in a Vietnamese population. Journal of Maternal-Fetal and Neonatal Medicine, 31(12), 1586-1594. https://doi.org/10.1080/1476705 8.2017.1320984

Jones, R., Haardörfer, R., Ramakrishnan, U., Yount, K. M., Miedema, S., \& Girard, A. W. (2019). Women's empowerment and child nutrition: The role of intrinsic agency. SSM - Population Health, 9. https://doi.org/10.1016/j.ssmph. 2019.100475

Kabeer, N. (1999). Resources , Agency, Achievements: Reflections on the Measurement of Women' s Empowerment, 30(May), 435-464.

Katepa-Bwalya, M., Mukonka, V., Kankasa, C., Masaninga, F., Babaniyi, O., \& Siziya, S. (2015). Infants and young children feeding practices and nutritional status in two districts of Zambia. International Breastfeeding Journal, 10(1), 1-8.

https://doi.org/10.1186/s13006015-0033-X

KEPPN. (2017). PEDOMAN DAN STANDAR ETIK PENELITIAN DAN PENGEMBANGAN

KESEHATAN NASIONAL.

Retrieved from

http://keppkn.kemkes.go.id/

Kitano, N., Nomura, K., Kido, M., Murakami, K., Ohkubo, T., Ueno, M., \& Sugimoto, M.
(2016). Combined effects of maternal age and parity on successful initiation of exclusive breastfeeding. Preventive Medicine Reports, 3 , 121-126.

https://doi.org/10.1016/j.pmedr. 2015.12.010

Liswati, E. M. (2016). Hubungan Karakteristik Ibu dengan Status Gizi Anak Balita yang Memiliki Jamkesmas di Desa Tegal Giri Kecamatan Nogosari Kabupaten Boyolali. Universitas Muhammadiyah Surakarta.

Mohidul Islam, Shahinur Rahman, Kamruzzaman, Mominul Islam, A. S. (2013). Effect of maternal status and breastfeeding practices on infant nutritional status - a cross sectional study in the south-west region of Bangladesh. Pan African Medical Journal, 8688, 1-9. https://doi.org/10.11604/pamj.2 013.16.139.2755

Nadkarni, R. (2015). Impact Of Maternal Demographics On Infant Feeding Habits In American Samoa. EliScholar A Digital Platform for Scholarly Publishing at Yale Public, (January).

Rasoolimanesh, S. M., \& Ali, F. (2018). Partial least squares structural equation modeling in hospitality and tourism David. Journal of Hospitality and Tourism Technology, 9(3), 238248.

https://doi.org/10.1108/JHTT10-2018-142

Riskesdas. (2018). Hasil Utama Riset Kesehatan Dasar. Kementrian Kesehatan Republik Indonesia, 1-100. https://doi.org/1 Desember 2013

Sarstedt, M., Ringle, C. M., \& Hair, 
J. F. (2020). Partial Least Squares Structural Equation Modelling. Handbook of Market Research.

https://doi.org/10.1007/978-3319-05542-8

Sjarif, D. R., Yuliarti, K., \& Iskandar, W. J. (2019). Daily consumption of growing-up milk is associated with less stunting among Indonesian toddlers, 28(1), 70-76.

Sukmawati,

Hendrayati,

Chaerunnimah, \& Nurhumaira. (2018). Status Gizi Ibu Saat Hamil, Berat Badan Lahir Bayi dengan Stunting Pada Balita. Media Gizi Pangan, 25, 18-25. Retrieved from https://media.neliti.com/media/p ublications/265332-status-giziibu-saat-hamil-berat-badan-18054beb3.pdf

Tanaka, J., Yoshizawa, K., Hirayama, K., Karama, M., \& Wanjihia, V. (2019). Relationship between dietary patterns and stunting in preschool children: a cohort analysis from Kwale , Kenya. Public Health, 173, 58-68. https://doi.org/10.1016/j.puhe.2 019.05.013

Utami, R. A., Setiawan, A., \& Fitriyani, P. (2019). Identifying causal risk factors for stunting in children under five years of age in South Jakarta, Indonesia. Enfermeria Clinica, (xx), 6-11. https://doi.org/10.1016/j.enfcli.2 019.04.093

Yang, Y. Y., Kaddu, G., Ngendahimana, D., Barkoukis, H., Freedman, D., Lubaale, Y. A. M., ... Bakaki, P. M. (2018). Trends and determinants of stunting among under-5s : evidence from the 1995,2001 , 2006 and 2011 Uganda Demographic and Health Surveys, 2010(3). https://doi.org/10.1017/S136898 0018001982 